Bangladesh J. Bot. 49(4): 1013-1019, 2020 (December)

\title{
CHARACTERIZATION OF CHLOROPHYLL DEFICIENT MUTANTS IN MUNGBEAN (VIGNA RADIATA (L.) WILCZEK)
}

\author{
Mohammad RafiQ WANI* \\ Department of Botany, Abdul Ahad Azad Memorial Degree College Bemina-190 018, \\ Cluster University Srinagar, Jammu and Kashmir, India
}

Keywords: Mungbean, Chlorophyll mutations, Mutagenic effectiveness, Chemical mutagens

\begin{abstract}
A wide spectrum of chlorophyll mutants was obtained in $\mathrm{M}_{2}$ generation following mutagenesis with MMS, HZ and SA. All these chlorophyll deficient mutants were lethal except maculata, viridis and virescent. MMS treatments induced the highest frequency of chlorophyll mutations followed by HZ and SA. The frequency of chlorophyll mutations was dose dependent and increased with increasing concentrations of all the three mutagens utilized. Chlorina followed by xantha outnumbered the other types of chlorophyll mutants with all the three mutagens. Based on effectiveness, the order of mutagens was HZ > SA > MMS. Two criteria viz., pollen sterility $(\mathrm{Mp} / \mathrm{S})$ and seedling injury $(\mathrm{Mp} / \mathrm{I})$ were taken into consideration to determine the efficiency of the mutagens. With regard to these criteria, MMS mutagen was found to be the most efficient followed by $\mathrm{HZ}$ and SA. Lower concentrations of all the three mutagens were most effective and efficient in inducing chlorophyll mutations.
\end{abstract}

\section{Introduction}

Mungbean (Vigna radiata (L.) Wilczek) holds an important position among the Vigna or the pulse family. It is an ancient and well-known crop among the Asian countries for its dietary or nutritional value (Patel et al. 2015). It is also an excellent source of high quality and easily digestible proteins with a seed protein content ranging from 18 - 22 per cent (Kadam et al. 2015). Mungbean is widely grown in countries of South and Southeast Asia especially China, India, Pakistan, Myanmar, Thailand and Vietnam. In India, mungbean was grown over an area of 4.30 million hectares with the production of 2.07 million tonnes in 2016 - 2017 (Annual Report 20162017). The average yield of $481 \mathrm{~kg} / \mathrm{ha}$ is low and is not sufficient to meet the growing demand. In order to break the yield plateau in mungbean, efforts are needed to develop high yielding varieties with appropriate growth habit. The possibility offered by mutagenic agents to develop new mutant varieties with improved agronomical traits such as larger seed size, high yield and resistance to diseases is of extreme importance. Moreover, the mutants obtained could become an important genetic resource for breeding, gene discovery and functional analysis of various genes.

Chlorophyll mutants are used as markers in genetic, physiological and biochemical investigations. They are most frequently observed and easily identified factorial mutations in $\mathbf{M}_{2}$ generation. Comparative study of induced chlorophyll mutation frequency in $\mathrm{M}_{2}$ generation is the most dependable index for determining the extent of induced genetic changes in mutagen treated population (Gustaffson 1954). Several authors have reported the occurrence of different types of chlorophyll mutations in $\mathbf{M}_{2}$ generation following mutagenic treatments (Khan and Tyagi 2009, Patial et al. 2017, Ramchander et al. 2018).

Chemical mutagens induce higher frequency of chlorophyll mutations than radiations as observed in urdbean (Arulbalachandran and Mullainathan 2009), chickpea (Kharkwal 1998) and lentil (Wani 2017). Chemical mutagens are not only mutagenic themselves but also affect mutation in specific ways when combined with radiations (Reddy and Smith 1984). The usefulness of a mutagen depends both on its effectiveness and efficiency. Mutagenic effectiveness

*Author for correspondence: <botanyrafiq@gmail.com> 
relates mutagen dose to the mutational events, while mutagenic efficiency gives an idea of genetic damage in relation to biological damage caused in $M_{1}$ generation (Konzak et al. 1965). Although these are two different properties, yet the usefulness of a mutagen in plant breeding programmes depends on both of them. The present investigation was undertaken to study the frequency and spectrum of chlorophyll mutations and to compare the mutagenic effectiveness and efficiency of different mutagens in $\mathrm{M}_{2}$ of mungbean subsequent to mutagenesis with MMS, $\mathrm{HZ}$ and SA.

\section{Materials and Methods}

A field experiment was conducted during the summer seasons of 2005, 2006 and 2007 at the University Agricultural Farm, Aligarh Muslim University, Aligarh, India. Dry and healthy seeds of mungbean (Vigna radiata (L.) Wilczek) var. Pusa Baisakhi, pre-soaked in distilled water for 9 hrs, were treated with three chemical mutagens viz., methylmethane sulphonate (MMS), hydrazine hydrate (HZ) and sodium azide (SA) for $6 \mathrm{hrs}$. The concentrations used for MMS ranged from 0.1 - $0.4 \%$, whereas these were $0.01-0.04 \%$ for HZ and SA. The solutions of MMS and HZ were prepared in phosphate buffers of $\mathrm{pH} 7$, whereas SA solution was prepared in phosphate buffer adjusted to $\mathrm{pH}$ 3. To facilitate uniform absorption, large quantities of the solution of mutagens approximately three times the volume of the seeds were used. Following these treatments, the seeds were thoroughly washed in running tap water to remove the residual mutagen from seed surface. The treated seeds were directly sown in the field along with untreated control. Three replications of 100 seeds per treatment were sown in complete randomized block design (CRBD) to raise $M_{1}$ generation. The $M_{1}$ plants were harvested separately and the seeds were sown in next season in plant progeny rows to raise $\mathrm{M}_{2}$ generation. The distance between the seeds in a row and between the rows was kept at 30 and $60 \mathrm{~cm}$, respectively.

Chlorophyll mutations were scored in $\mathrm{M}_{2}$ generation, when seedlings were 7 - 15 days old. They were identified and classified according to Gustafsson (1940). The frequency of such chlorophyll mutations was calculated by the following formula:

$$
\text { Mutation frequency }(\%)=\frac{\text { Number of mutant seedlings }}{\text { Total number of } \mathrm{M}_{2} \text { seedlings }} \times 100
$$

Formulae suggested by Konzak et al. (1965) were used to evaluate the mutagenic effectiveness and efficiency of the mutagens.

$$
\begin{gathered}
\text { Mutagenic effectiven ess }=\frac{\text { Rate of mutation }(\mathrm{Mp})}{\text { Duration of treatment } \times \text { concentrat ion }} \\
\text { Mutagenic efficiency }=\frac{\text { Rate of mutation }(\mathrm{Mp})}{* \text { Biological damage in } \mathrm{M}_{1} \text { generation }}
\end{gathered}
$$

*Biological damage: For measuring biological damage, two different criteria were used:

(i) Injury - i.e. percentage reduction in seedling height $(\mathrm{Mp} / \mathrm{I})$

(ii) Sterility - i.e. percentage reduction in pollen fertility $(\mathrm{Mp} / \mathrm{S})$

Pollen fertility was estimated by staining the pollen grains with $1 \%$ aceto-carmine solution. Pollen grains which took stain and had regular outline were considered as fertile, whereas shrunken, empty and unstained ones were treated as sterile.

\section{Results and Discussion}

Chlorophyll mutations represent reliable indices for evaluation of genetic effects of mutagens and are useful in assessing the potency of a mutagen. From breeder's point of view, the frequency 
of chlorophyll mutants expressed as per cent of $\mathrm{M}_{2}$ population seems to be more realistic and helpful. During the first 15 days at seedling stage, chlorophyll mutations were recorded in the field after MMS, HZ and SA treatments. The spectrum of chlorophyll mutants included albina, chlorina, maculata, xantha, virescent and viridis. Maculata, viridis and virescent survived up to maturity and produced a few seeds, while albina, xantha and chlorina died at seedling stage. A brief description of such chlorophyll mutants is as follows:

Albina: Lethal mutant, white leaves of seedlings, survived for 8 - 10 days after germination.

Chlorina: Light green first pair of seedling leaves, emerging leaves were also light green and became darker with the approach of maturity, seedlings died within 15 days.

Maculata: Yellow or whitish dots on leaves. Plants were vigorous in growth, late in maturity and produced a few seeds.

Xantha: Yellow colored leaves, seedlings survived for 10 - 15 days only.

Virescent: White or light-yellow colored leaves with patches of yellowish green color. The yellowish or light green patches completely disappeared and the normal color was recuperated. They were as vigorous as the normal plants and set seeds.

Viridis: Viridine green color of leaves, reduced in height, slow growing with low seed yield. Amongst the six types of chlorophyll mutants recorded in $\mathrm{M}_{2}$ generation, 'chlorina' followed by 'xantha' types were predominant in all the three mutagens. Saha et al. (2015) reported that electron beam and gamma irradiation induced a greater number of 'chlorina' mutations in variety Vijay of chickpea, while Khan et al. (2005) reported that chemical mutagens induced higher frequency of 'chlorina' mutants in $\mathrm{M}_{2}$ generation of chickpea. Occurrence of 'chlorina' mutants in various crop species are attributed to impaired chlorophyll biosynthesis, chlorophyll degradation and deficiency of carotenoids (Bevins et al. 1992).

Among the mutagens, MMS induced the higher frequency and wider spectrum of chlorophyll mutations. Prakash and Khanure (1999) in rice bean and Waghmare and Mehra (2001) in Lathyrus sativus have reported similar results where alkylating agents had produced more frequency of chlorophyll mutations than gamma rays. The high incidence of chlorophyll mutations induced by MMS could be due to its specificity to affect certain regions of chromosomes. High frequency of chlorophyll mutations is due to the selective action of chemical and physical mutagens on genes responsible for chlorophyll development or on guanine in the G-C rich chloroplast genome (Chopra 2005). Generally, the nuclear genes control the synthesis of chlorophyll in plants through long chain of biochemical reactions which involve number of gene loci (Svetleva 2004). The mutation in nuclear gene can change the genetic resistance of cytoplasmic DNA present in chloroplasts or mitochondria (Harten 1998). According to Swaminathan et al. (1962), preferential action of chemical mutagens in chlorophyll developing genes is responsible for increase in chlorophyll mutations.

A linear relationship between chlorophyll mutations frequency and dose was observed with all the three mutagens (Table 1). Similar dose dependent increase in chlorophyll mutation frequency was reported by Kharkwal (1998) in chickpea, John (1999) in cowpea and Das and Kundagrami (2000) in grasspea. However, higher frequency of chlorophyll mutations with medium or lower doses of mutagens were reported by Nadarajan et al. (1982) in pigeon pea. The frequency of chlorophyll mutations induced by SA was much less as compared to MMS and HZ. Contrarily, Awan et al. (1980) observed a high frequency of chlorophyll mutations in rice after sodium azide (SA) treatment. The disparity could be due to altered treatment conditions of the mutagens. The low chlorophyll mutations frequency in SA treatments may be due to the inhibition of certain enzymes like catalase and peroxidase and increased peroxide concentration in the cells (Kleinhofs et al. 1978). Higher frequency of chlorophyll mutations with medium or lower doses of 


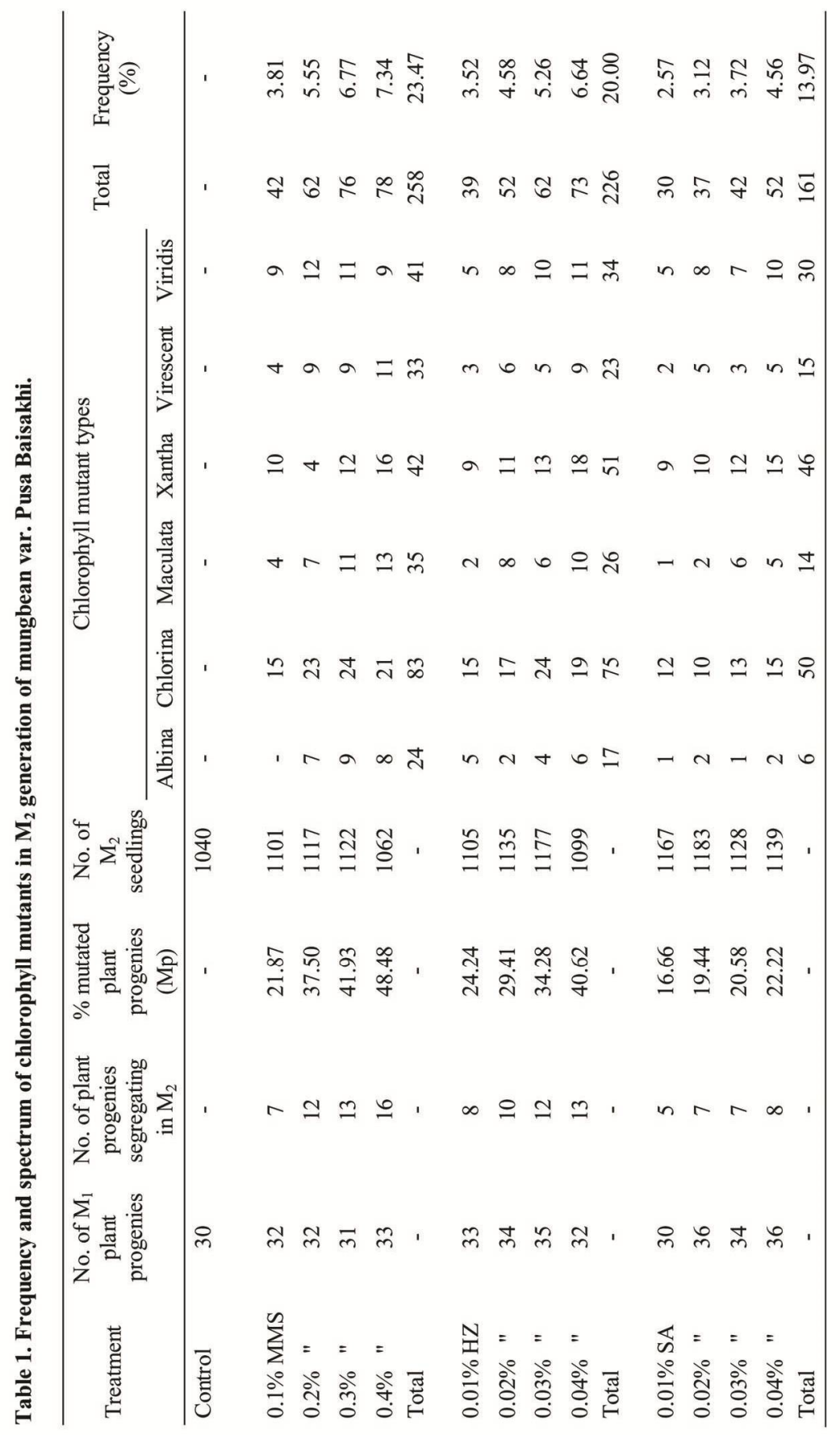


mutagens were earlier reported by Arora and Kaul (1989) in Pisum sativum and Kharkwal (1998) in Cicer arietinum.

Data on effectiveness and efficiency of various mutagens is presented in Table 2. It was found that both mutagenic effectiveness and efficiency were higher at lower doses of all the mutagens. This is because the lower dose may cause relatively less biological damage enabling organism to express the induced gene mutations successfully. The estimates of mutagenic effectiveness ranged from 20.20 to 36.45 in MMS treatments, whereas the effectiveness of HZ and SA treatments ranged from 169.25 to 404.00 and 92.58 to 277.66, respectively. Mutagenic effectiveness decreased at the highest concentration of all the three mutagens. The order of mutagens based upon effectiveness was HZ > SA > MMS. HZ was also reported to be an effective mutagen in maize (Chandrashekhar and Reddy 1971) and barley (Kak and Kaul 1975). Contrary to the earlier reports of Waghmare and Mehra (2001), MMS in the present study, proved less effective than HZ and SA. The difference in mutagen concentration and/or genotypic response seems to be the reason for its low effectiveness.

Table 2. Effectiveness and efficiency of the mutagens in $M_{2}$ generation of mungbean var. Pusa Baisakhi.

\begin{tabular}{lcccccc}
\hline Treatment & $\begin{array}{c}\text { \% pollen } \\
\text { sterility (S) }\end{array}$ & $\begin{array}{c}\text { \% seedling } \\
\text { injury (I) }\end{array}$ & $\begin{array}{c}\text { \% mutated } \\
\text { plant progenies } \\
(\mathrm{Mp})\end{array}$ & $\begin{array}{c}\text { Mutagenic } \\
\text { effectiveness } \\
\text { Mp/t.c }\end{array}$ & Mp/S & Mp/I \\
\hline $0.1 \%$ MMS & 12.65 & 4.25 & 21.87 & 36.45 & 1.72 & 5.14 \\
$0.2 \%$ " & 22.12 & 10.63 & 37.50 & 31.25 & 1.69 & 3.52 \\
$0.3 \%$ " & 25.25 & 12.76 & 41.93 & 23.29 & 1.66 & 3.28 \\
$0.4 \%$ " & 27.52 & 17.02 & 48.48 & 20.20 & 1.76 & 2.84 \\
Average & 21.88 & 11.16 & 37.44 & 27.79 & 1.70 & 3.69 \\
$0.01 \%$ HZ & 13.62 & 3.12 & 24.24 & 404.00 & 1.77 & 7.76 \\
$0.02 \%$ " & 18.07 & 14.89 & 29.41 & 245.08 & 1.62 & 1.97 \\
$0.03 \%$ " & 21.66 & 18.08 & 34.28 & 190.44 & 1.58 & 1.89 \\
$0.04 \%$ " & 26.95 & 23.14 & 40.62 & 169.25 & 1.50 & 1.75 \\
Average & 20.07 & 14.80 & 32.13 & 252.19 & 1.61 & 3.34 \\
$0.01 \%$ SA & 10.80 & 5.31 & 16.66 & 277.66 & 1.54 & 3.13 \\
$0.02 \%$ " & 12.64 & 17.02 & 19.44 & 162.00 & 1.53 & 1.14 \\
$0.03 \%$ " & 17.84 & 21.27 & 20.58 & 114.33 & 1.15 & 0.96 \\
$0.04 \%$ " & 21.02 & 23.40 & 22.22 & 92.58 & 1.05 & 0.95 \\
Average & 15.57 & 16.75 & 19.72 & 161.64 & 1.31 & 1.54 \\
\hline
\end{tabular}

The degree of mutagenic efficiency varied depending upon the criteria selected for its estimation. Based on $\mathrm{Mp} / \mathrm{S}$ and $\mathrm{Mp} / \mathrm{I}$, MMS was found to be the most efficient mutagen as compared to $\mathrm{HZ}$ and SA (Table 2). Lower mutagenic concentrations proved more efficient than the moderate and highest ones. Konzak et al. (1965) in barley and Khan (1999) in black gram also reported the higher mutagenic efficiency at lower mutagenic doses. The higher efficiency at lower mutagenic doses is due to the fact that biological damage viz., seedling injury and pollen sterility increased with increasing doses at a faster rate than the mutations yielded. 
It can be concluded that highest mutagenic effectiveness and efficiency were observed at lower doses of all the mutagens utilized. Moreover, MMS mutagen was more successful in enhancing the frequency and spectrum of chlorophyll mutations as compared to HZ and SA. These chlorophyll mutants could be exploited in different mutation breeding programmes for inducing such viable mutations that could lead to the genetic improvement of mungbean crop besides assisting in functional analysis of different genes.

\section{Acknowledgements}

The author is grateful to the Chairman, Department of Botany, Aligarh Muslim University, Aligarh, India for providing necessary research and laboratory facilities. He is also indebted to his research supervisor Dr. Samiullah Khan, Professor, Department of Botany, Aligarh Muslim University, Aligarh, India for providing valuable guidance and constant support during the successful completion of this work.

\section{References}

Annual Report 2016-2017. In: Government of India, Ministry of Agriculture and Farmers Welfare, Department of Agriculture, Cooperation and Farmers Welfare, Directorate of Pulses Development, Vindhyachal Bhavan, India.

Arora R and Kaul MLH 1989. Mutagen induced chlorophyll deficiency in Pisum sativum. Cytobios 57: 189199.

Arulbalachandran D and Mullainathan L 2009. Chlorophyll and morphological mutants of black gram (Vigna mungo (L.) Hepper) derived by gamma rays and EMS. J. Phytol. 1: 236-241.

Awan MA, Konzak CF, Rutger JN and Nilan RA 1980. Mutagenic effects of sodium azide in rice. Crop Science 20: 663-668.

Bevins M, Yang CM and Markwell J 1992. Characterization of a chlorophyll deficient mutant of sweet clover (Melilotus alba). Plant Physiol. Biochem. 30: 327-331.

Chandrashekhar VSC and Reddy GM 1971. Specific locus mutations in maize by chemical mutagenesis. Curr. Sci. 40: 136-137.

Chopra VL 2005. Mutagenesis: Investigating the processing the outcome for crop improvement. Current Science 89: 353-359.

Das PK and Kundagrami S 2000. Frequency and spectrum of chlorophyll mutations in grasspea induced by gamma rays. Indian J. Genet. 60: 239-241.

Gustaffson A 1954. Mutation, variability and population structure. Acta Agric. Scand. 4: 601-631.

Gustafsson A 1940. A mutation system of the chlorophyll apparatus. Lund. Univ. Arsskr. N.F. Avd. 2. 36: $1-40$.

Harten AM 1998. Mutation breeding theory and practical applications. Cambridge University Press, Cambridge.

John SA 1999. Mutation frequency and chlorophyll mutations in parents and hybrids of cowpea following gamma irradiation. Indian J. Genet. 59: 357-361.

Kadam GS, Patil AJ and Girase VS 2015. Gene effects for yield and yield attributing characters in intraspecific crosses of mungbean (Vigna radiata (L.) Wilczek). J. Food Legumes 28: 220-222.

Kak SN and Kaul BL 1975. Mutagenic activity of hydrazine and its combinations with maleic hydrazide and X-ray in barley. Cytobios 12: 123-128.

Khan MH and Tyagi SD 2009. Studied on induction of chlorophyll mutations in soybean (Glycine max (L.) Merrill). Front. Agric. China 3: 253-258.

Khan MN 1999. Mutagenic effectiveness and efficiency of EMS, gamma rays and their combinations in black gram (Vigna mungo (L.) Hepper). Adv. Plant Sci. 12: 203-205. 
Khan S, Wani MR, Bhat MD and Parveen K 2005. Induced chlorophyll mutations in chickpea (Cicer arietinum L.). Int. J. Agric. Biol. 7: 764-767.

Kharkwal MC 1998. Induced mutations in chickpea (Cicer arietinum L.). II. Frequency and spectrum of chlorophyll mutations. Indian J. Genet. 58: 465-474.

Kleinhofs A, Owais WM and Nilan RA 1978. Azide. Mutation Research 55: 165-195.

Konzak CF, Nilan RA, Wagner J and Foster RJ 1965. Efficient chemical mutagenesis. Rad. Bot. 5 (Suppl.): 49-70.

Nadarajan N, Sathupati R and Shivaswamy N 1982. Investigation on induced macromutations in Cajanus cajan. Madras Agric. J. 69: 713-717.

Patel U, Trivedi, PB and Pathak AR 2015. Heterosis study for yield and its contributing characters in mungbean (Vigna radiata (L.) Wilczek). J. Food Legumes 28: 223-227.

Patial M, Thakur SR, Singh KP and Thakur A 2017. Frequency and spectrum of chlorophyll mutations and induced variability in ricebean (Vigna umbellata Thunb, Ohwi and Ohashi). Legume Research 40: 39-46.

Prakash BG and Khanure SK 1999. Isolation of mutants and their frequencies under $\mathrm{M}_{2}$ generation in rice bean (Vigna umbellata L. Thunb). Karnataka J. Agriculture Science 12:38-42.

Ramchander L, Shunmugavalli N, Muthuswamy A and Rajesh S 2018. Mutagenic effectiveness of chlorophyll and viable mutants in $\mathrm{M}_{2}$ generation of black gram (Vigna mungo (L.) Hepper). Int. J. Pure App. Biosci. 6: 842-844.

Reddy CS and Smith JD 1984. Mutagenic effectiveness and efficiency of hydrazine and ethylmethane sulphonate in Sorghum bicolor. Indian J. Genet. 44: 49-54.

Saha AJ, Reddy KS, Petwal PC and Dwivedi J 2015. Identification of novel mutants through electron beam and gamma irradiation in chickpea (Cicer arietinum L.). J. Food Legumes 28: 99-104.

Svetleva DL 2004. Induction of chlorophyll mutants in common bean under the action of chemical mutagens ENU and EMS. J. Central European Agriculture 5: 85-90.

Swaminathan MS, Chopra VL and Bhaskaran S 1962. Chromosome aberrations and frequency and spectrum of mutations induced by EMS in barley and wheat. Indian J. Genet. 22: 192-207.

Waghmare VN and Mehra RB 2001. Induced chlorophyll mutations, mutagenic effectiveness and efficiency in Lathyrus sativus L. Indian J. Genet. 61: 53-56.

Wani MR 2017. Induced chlorophyll mutations, comparative mutagenic effectiveness and efficiency of chemical mutagens in lentils (Lens culinaris Medik). Asian Journal of Plant Sciences 16: 221-226.

(Manuscript received on 22 October, 2018; revised on 24 March, 2020) 